\title{
CONSEQUENCIALISMO, PRAGMATISMO E ANÁLISE ECONÔMICA DO DIREITO: SEMELHANÇAS, DIFERENÇAS E ALGUNS EQUÍVOCOS
}

\section{CONSEQUENTIALISM, PRAGMATISM AND ECONOMIC ANALYSIS OF LAW: SIMILARITIES, DIFFERENCES AND SOME MISCONCEPTIONS}

\section{RESUMO}

\author{
Thiago Cardoso Araujo ${ }^{1}$ \\ Fernando Ferreira Jr. ${ }^{2}$ \\ Lucas Dos Reis Montenegro ${ }^{3}$
}

O direito brasileiro se depara, hoje, com a importação de teorias como o consequencialismo, o pragmatismo e a Análise Econômica do Direito. O objetivo deste artigo é indicar a existência de uma tendência de deformação dessas teorias importadas, que passariam por uma espécie de brasilianização. Ocorre uma antropofagia - a deglutição de teorias estrangeiras, e o seu refazimento à brasileira -, resultando numa possível interpretação equivocada de tais teorias. Para tal, delimita os conceitos referentes a tais teorias, bem como explicita a forma como elas vêm sendo usadas no Brasil.

Palavras-chave: Consequencialismo. Pragmatismo. Análise Econômica do Direito. Delimitação conceitual.

\begin{abstract}
Brazilian law is currently faced with the importation of theories such as consequentialism, pragmatism and the Economic Analysis of Law. The purpose of this article is to indicate the existence of a deformation trend of these imported theories, which would undergo a kind of brazilianization. An anthropophagy occurs - the swallowing of foreign theories, and their remake in Brazilian style -, resulting in a possible misinterpretation of such theories. To this end, it delimits the concepts referring to such theories, as well as explains how they have been used in Brazil.
\end{abstract}

Keywords: Consequentialism. Pragmatism. Law and Economics. Conceptual Delimitation.

\footnotetext{
${ }^{1}$ Professor de Pós-Graduação em Direito do Rio de Janeiro da Fundação Getúlio Vargas (FGV Direito Rio - Rio de Janeiro, RJ, Brasil)Doutor e Mestre pela UERJ. Professor de Pós-Graduação em Direito do Rio de Janeiro da Fundação Getúlio Vargas (FGV Direito Rio). Procurador do Estado do Rio de Janeiro. Advogado.Afiliação: Fundação Getúlio Vargas - FGV-RJ. Lattes: http://lattes.cnpq.br/6746850802809922. E-mail: araujo.c.thiago@gmail.com

${ }^{2}$ Mestrando em Direito da Regulação pela Fundação Getúlio Vargas (FGV Direito Rio). Assessor Jurídico da Secretaria de Estado de Infraestrutura. Advogado. Afiliação: Fundação Getúlio Vargas - FGV-RJ Email:fernandosfjr@gmail.com

${ }^{3}$ Mestrando em Direito da Regulação pela Fundação Getúlio Vargas (FGV Direito Rio). Especialista em Direito Administrativo pela UCAM. Assessor Jurídico da Secretaria de Estado de Infraestrutura. Afiliação: Fundação Getúlio Vargas - FGV-RJ. Lattes: http://lattes.cnpq.br/3322970298090550. E-mail:lucasr.montenegro @gmail.com
} 


\section{Introdução}

O direito brasileiro se deparou com o fato de que consequências importam. Se o padrão do jurista brasileiro era o do dogmatismo franco-alemão, hoje ganha força o padrão empirista angloamericano ${ }^{4}$.

A dogmática, que antes ocupava eixo central da investigação jurídica brasileira, hoje passa a ser vista, por alguns, como vetusta, mesmo ultrapassada.

A Lei de Introdução às Normas de Direito Brasileiro - LINDB foi, inclusive, alterada para normatizar a importância das consequências práticas do processo de tomada de decisão ${ }^{5}$.

Não basta ao moderno jurista brasileiro a investigação dos institutos. Cresce a necessidade de uma nova metodologia, menos autocentrada e mais aberta aos influxos de outras disciplinas do conhecimento humano, como a economia ${ }^{6}$.

Autores como Gustavo Binenbojm chegam a afirmar que o Direito (especialmente o Direito Público) brasileiro vive, hoje, um giro pragmático ${ }^{7}$. Esse giro, essa mudança, esse novo olhar ao Direito orbita de três conceitos, muitas vezes utilizados de forma equivocadamente fungível: Análise Econômica do Direito (AED); Pragmatismo Jurídico; e Consequencialismo,

A viagem das ideias teóricas nem sempre se dá, todavia, sem maiores turbulências. Ao adentrar o território nacional, teme-se que tais teorias passam por uma espécie de antropofagia ${ }^{8}$,

\footnotetext{
${ }^{4}$ A afirmação que abre o presente artigo pode ser colocada entre parênteses. Não se trata de uma descoberta das consequências pelo direito brasileiro. Aliás, mostra-se até mesmo implausível que, ao longo de séculos de experiência, os juristas brasileiros nunca tenham se dado conta dos impactos sociais, econômicos e políticos de suas decisões. As consequências de decisões e medidas legais sempre estiveram no horizonte de consciência do direito brasileiro. Simples consulta ao clássico "Hermenêutica e interpretação do direito", de Carlos Maximiliano prova o ponto: "[p]reocupa-se a Hermenêutica, sobretudo depois que entraram em função de exegese os dados da Sociologia, com o resultado provável de cada interpretação. Toma-o em alto preço: orienta-se por ele; varia tendoo em mira, quando o texto admite mais de um modo de o entender e aplicar. Quanto possível, evita uma consequência incompatível com o bem geral; adapta o dispositivo às ideias vitoriosas entre o povo em cujo seio vigem as expressões de direito sujeitas a exame". (MAXIMILIANO, Carlos. Hermenêutica e aplicação do direito. Rio de Janeiro: Forense, 2011, p. 165). Nesse sentido, diga-se, trivial, o consequencialismo não representa nenhuma novidade. No entanto, o consequencialismo de que falaremos neste capítulo, e que foi incorporado ao direito brasileiro por meio da reforma da LINDB, não é esse tipo trivial de consequencialismo. Não obstante, o alerta se faz necessário de saída para que não se corra o risco — provavelmente já materializado — da abrasileirização do instituto.

${ }^{5}$ V. art. 20, LINDB, fruto da reforma trazida pela lei $\mathrm{n}^{\mathrm{o}} 13.655 / 2018$ : "Nas esferas administrativa, controladora e judicial, não se decidirá com base em valores jurídicos abstratos sem que sejam consideradas as consequências práticas da decisão".

${ }^{6}$ MENDONÇA, José Vicente Santos de. A verdadeira mudança de paradigma do direito administrativo brasileiro: do estilo tradicional ao novo estilo. Revista de Direito Administrativo. Rio de Janeiro, v. 265, p. 178/198, jan/abr. de 2014.

7 BINENBOJM, Gustavo, Uma teoria do direito administrativo direitos fundamentais, democracia e constitucionalização, Rio de Janeiro; São Paulo: Renovar, 2008.

${ }^{8}$ Com a proximidade do ano de 2022, é auspicioso para se falar de antropofagia, pois se trata do ano centenário da Semana de Arte Moderna de 1922, que prefigurou o famoso Manifesto Antropofágico, de 1928. V. Revista de
} 
gerando uma espécie de visão abrasileirada do instituto, versão essa que pode repercutir por meio de um processo de replicação acadêmica ${ }^{9}$.

A histórica intelectual brasileira não é estranha à importação de ideias fora do lugar, como chama Roberto Schwarz. Durante os estertores do Império, causou perplexidade a absorção de ideias de matiz liberal por uma sociedade predominantemente escravagista, resultando em uma "química também singular"

Sugere-se, nesse artigo, uma imagem que traduz o atual quadro: uma nova antropofagia, que devora o consequencialismo, o pragmatismo e a AED, substitui o que seria a velha antropofagia, deglutidora de teorias deontológicas como a Teoria dos Princípios.

Além da malversação acadêmica, há, ainda, o risco de utilização de teorias novas como o consequencialismo de forma a fundamentar particularismos judiciais, a exemplo da crítica que se faz à aplicação da Teoria dos Princípios ${ }^{11}$. É o medo de que o consequencialismo se torne o consequenciachismo ${ }^{12}$.

Verifica-se, portanto, a existência de uma verdadeira nova onda importadora .Surge, contudo, a preocupação: será que os institutos recém-importados serão utilizados de forma correta?

É preciso delimitar os conceitos de consequencialismo, pragmatismo e Análise Econômica do Direito, de forma adequada, de modo a compreender suas semelhanças e diferenças.

Se as ideias se encontram fora do lugar, preciso, pois, tentar pô-las dentro do lugar. Esse é o objetivo do artigo. Não se trata apenas de preciosismo teórico. As ideias têm consequências ${ }^{13}$ : jurisprudência pátria chega, inclusive, a utilizar-se de tais conceitos de forma fungível ${ }^{14}$.

A explanação seguirá uma linha conforme a anterioridade cronológica: será, portanto, analisado, primeiramente, o consequencialismo, para ser enfrentado, após, o pragmatismo jurídico e, por fim, a Análise Econômica do Direito. A ordem facilitará, também, na compreensão de o porquê haver uma certa confusão entre os termos, especialmente em relação ao consequencialismo e ao pragmatismo.

\footnotetext{
Antropofagia, v. 1, n. 1, maio de 1928. Disponível em: <https://digital.bbm.usp.br/bitstream/bbm/7064/ 1/45000033273.pdf>. Acesso em 2 de março de 2021.

${ }^{9}$ É o caso, por exemplo, do pós-positivismo, tido como lugar comum no Brasil, e cuja existência é tida como impossível na academia estrangeira. Nesse sentido: PETROSKI, Karen. Is Post-Positivism possible? German Law Review, v. 12, n. 2, p. 663-692, fev. de 2011.

${ }^{10}$ SCHWARZ, Roberto. As ideias fora do lugar. In: “Ao vencedor as batatas”, São Paulo: Duas Cidades, 4 a edição, 1992, pp. 1-16.

${ }^{11}$ SUNDFELD, Carlos Ari. Princípio é preguiça? In: Ronaldo Porto Macedo Jr. e Catariana Barbieri (org). Direito e interpretação - racionalidades e instituições. São Paulo: Saraiva, 2011, pp. 287-305.

12 MENDES, Conrado Hübner. Jurisprudência impressionista. Época, 14 set. 2018. Disponível em: $<$ https://epoca.globo.com/conrado-hubner-mendes/jurisprudencia-impressionista-23066592> . Acesso em 17 de fev. de 2021.

${ }^{13}$ Em apropriação ao título da edição brasileira da obra de WEAVER, Richard M. As ideias têm consequências

${ }^{14} \mathrm{O}$ tema será tratado, oportunamente, na seção anterior à conclusão. São Paulo: É Realizações, 2012.
} 
A ideia deste artigo não é realizar juízos avaliadores das teorias. Ao contrário: o intuito é apresentá-las em sua melhor forma possível, evitando espantalhos ${ }^{15}$.

O artigo será desenvolvido da seguinte forma: (i) a primeira seção sucintamente diferenciará o common law do direito continental, relacionando os diferentes sistemas com formas diferentes de pensar o fenômeno jurídico; (ii) a segunda parte definirá o consequencialismo, o pragmatismo e a Análise Econômica do Direito; e (iii) a terceira seção trará exemplos da aplicação de decisões consequencialistas no Brasil, de modo a observar o que parece ser uma utilização equivocadamente fungível do termo para, por fim, concluir.

\section{Direito Anglo-Americano e Direito Continental Europeu: dois sistemas, duas formas de pensar}

Nosso Direito segue a tradição dos jurisconsultos romanos, que, deparados com a prática jurídica do dia a dia, criaram uma série de institutos e normas para avalizar a práxis, normas que, posteriormente, sofreram grandes processos de codificação. O chamado sistema continental, de influxo romano e, posteriormente, francês e alemão, assim, parte de um raciocínio dedutivo e de subsunção, no qual os operadores buscam enquadrar fatos da experiência jurídica em institutos.

O Direito Anglo-Saxão, chamado common law, por sua vez, surge da experiência das cortes inglesas, que se deparavam com conflitos jurídicos do cotidiano e, a partir deles, extraíam generalizações a serem aplicadas em casos subsequentes. Predomina o raciocínio indutivo. Difere de sua contraparte Romana por não ter havido grandes processos de codificação. O Direito Inglês, passado posteriormente às colônias, é, desse modo, um direito das cortes.

A diferença entre os dois sistemas repercute no raciocínio e na pesquisa jurídicos. Nos países de tradição romano-germânica (tratados pela anglofonia como civil law), os tratados e comentários de autores jurídicos possuem natureza sistematizadora e de formulação de teorias gerais sobre códigos e legislações. O estudo do Direito, em tais países, reveste-se de uma natureza academicista.

Em países de Direito Anglo-Saxão (common law), por sua vez, não há grande quantidade de doutrina sistematizadora ${ }^{16}$, sendo o principal estudo o estudo de casos concretos. A educação

\footnotetext{
${ }^{15}$ A preocupação em tomar uma teoria em sua melhor forma possível é exemplificada por Coleman quando trata do debate positivismo v. jusnaturalismo, debate esse também tão afeto a caricaturas: "our immediate ambition should be to see if we might formulate the natural lawyer's claim charibaly so that it might be the source of insight rather than ridicule". (COLEMAN, Jules. The Architecture of Jurisprudence. The Yale Law Journal, v. 121, n. 1, 2011. Disponível em: https://www.yalelaw journal.org/pdf/1009 3fnvkd8i.pdf. Acesso em: 30 out. 2020, p. 7). ${ }^{16}$ Importante mencionar a notória exceção de Christopher Columbus Langdell, autor de obra sistematizadora sobre Teoria dos Contratos no âmbito da Common Law: Selection of cases on the law of Contracts. Boston: Little, Brown and Company, 1879. Mas ainda assim, o método é híbrido, pois voltava-se a uma sistematização a partir dos casos, que ainda ocupavam o papel de principal objeto de estudo.
} 
jurídica, aqui, dá ênfase à prática e à importância do que as cortes decidiram em determinado caso concreto $^{17}$.

O sistema da common law estaria, dessa forma, sensível à realidade prática e às consequências geradas pela aplicação do Direito ${ }^{18}$. Não à toa surgiu, nos Estados Unidos, o realismo jurídico norte-americano, segundo o qual a aplicação do Direito não se encerra "dentro das cortes", e nem mesmo dentro do sistema jurídico, sendo importante para o estudo do Direito a realidade na qual está inserida o ordenamento e, sobretudo, a realidade a qual está sujeita o decisor ${ }^{19}$.

O realismo jurídico é uma corrente de pensamento que tem nomes importantes como Oliver Wendel Holmes Jr., que exerceu, inclusive, o cargo de Juiz da Suprema Corte.

Didaticamente, podemos pensar no sistema anglo-americano como um direito da prática, ao passo que o direito continental europeu seria um direito das ideias. Ambas as formas de se pensar o fenômeno jurídico repercutem, como dito, tanto na vivência prática do Direito quanto no seu ensino e na sua metodologia.

\title{
2. Conceitos
}

\subsection{Consequencialismo}

Em um sentido superficial, o consequencialismo pode ser compreendido como uma classe de teorias normativas éticas cuja afirmação central é a ideia de que as consequências de determinada conduta deverão ser a medida de sua correição. Samuel Scheffler ${ }^{20}$ afirma que:

\begin{abstract}
"[c]onsequentialism, in its purest and simples form is a moral doctrine which says that the right act in any given situation is the one that will produce to he best overall outcome, as judged from an interpersonal standpoint which gives equal weight to the interests of everyone. Somewhat more precisely, we may think of a consequentialist theory of this kind as coming in two parts. First, it gives some principle for ranking overall states of affairs from best to worst from an impersonal standpoint, and then it says that the right act in any given situation is the one that will produce the highest-ranked state of affairs that the agent is in a position to produce". (SCHEFFLER, 1988, p. 8)
\end{abstract}

\footnotetext{
${ }^{17}$ Acerca da diferença entre os sistemas jurídicos, ver DAINOW, Joseph. The Civil Law and the Common Law: some points of comparison. The American Journal of Comparative Law, v. 15, n. 3, pp. 419-435. 1966-1967. Disponível em: <https://www.jstor.org/stable/838275>. Acesso em 17 de fev. de 2021.

${ }^{18}$ A pretensão de sensibilidade da common law à realidade fática pode ser enxergada, contudo, como uma leitura retrospectiva dos fatos históricos. Leitura essa influenciada pelos autores do Realismo Jurídico Norte-Americano, que procuram fundamentar suas pretensões teóricas na própria natureza da common law.

${ }^{19}$ Para maiores informações sobre o realismo jurídico norte-americano, ver: LEITER, Brian. Legal Realism, Hard Positivism, and the Limits of Conceptual Analysis. In: Naturalizing Jurisprudence: Essays on American Legal Realism and Naturalism in Legal Philosophy. Nova Iorque: Oxford University Press, 2007, p. 121-135.

${ }^{20}$ SCHEFFLER, Samuel. Consequentialism and its critics. Oxford: Oxford University Press, 1988, p. 8.
} 
Didaticamente, é importante distinguir os seguintes pontos: (i) a correção do ato é aferível por suas consequências em termos gerais; e (ii) avaliador considerará o ato bem-avaliado se, naquela circunstância, o agente produziu, segundo critérios determinados pelo avaliador, as melhores consequências possíveis.

Jussi Suikkanen $^{21}$, a seu turno, escreve que:

"[c]onsequentialist theories have two elements. According to the axiological element, agents' options can always be ranked in terms of how much aggregate value their consequences have. The second, normative element then stipulates that an act is right if and only if the agent does not have an option that would have a higher evaluative ranking”. (SUIKKANEN, 2009, p. 1)

A perspectiva consequencialista, levando em consideração a definição trazida, não é, observese, uma que mire uma situação ideal. Não: a avaliação das consequências toma por base uma ideia de melhor incremento possível do estado da arte atual.

É dizer, em outras palavras, que a ação tomada foi a melhor possível dentro do universo de cursos de ação disponíveis ao agente.

O consequencialismo está inserido dentro das filosofias morais. Enquanto filosofia moral, avalia a moralidade de determinado ato a partir do valor de suas consequências.

Pode-se falar em duas espécies de consequencialismo: (i) consequencialismo de atos; e (ii) consequencialismo de regras. O consequencialismo de atos examina cada ato individualmente à luz de seus resultados. O consequencialismo de regras, por sua vez, determina que a ação será moralmente adequada quando obedecer a uma regra cuja observância seja aquela a produzir o resultado desejado. Tal distinção deve ser levada em conta, pois será posteriormente retomada quando tratarmos de Análise Econômica do Direito.

Nele estão inseridas correntes filosóficas como o utilitarismo, talvez a filosofia de matiz consequencialista mais famosa, contra a qual se opôs John Rawls em seu livro A Theory of Justice ${ }^{22}$.

A rigor pode-se mesmo dizer que, nos últimos tempos, as correntes mais em voga da filosofia do direito oscilam pendularmente entre dois extremos: um de caráter utilitarista; o outro de matiz deontológico $^{23}$. É seguro afirmar que nessa faixa que vai de um extremo ao outro o

\footnotetext{
${ }^{21}$ SUIKKANEN, Jussi. Consequentalism, constraints and the good-relative-to: a reply to Mark Schroeder. Journal of Ethics \& Social Philosophy. Discussion note, mar. 2009.

${ }^{22}$ Ibidem, p. 2.

23 "Há muitos anos que os especialistas têm retratado, de maneira persistente, praticamente todas as ideias sobre justiça em um de dois continentes. Segundo essa cartografia, o território utilitarista é habitado por pontos de vista que estipulam uma meta e deduzem um conceito de justiça dessa meta ou objetivo, normalmente especificando um conjunto de princípios, regras e instituições que, espera-se, sejam úteis para a sua realização. A meta mais comentada nos últimos tempos tem sida a maximização da felicidade. Essa meta está formalizada no princípio de utilidade (ou princípio da maior felicidade), que é a ideia central da tradição utilitarista clássica. (...) O continente deontológico (no jargão da filosofia moral moderna) é o outro único território reconhecido. A categoria dos pontos de vista deontológicos está unida pela convicção de que a justiça é uma questão de deveres precisos que não podem ser sobrepujados por nenhuma outra consideração, nem mesmo pelo propósito de alcançar objetivos altamente desejáveis. O raciocínio rudimentar de onde brota esse conjunto de pontos de vista é que algumas coisas são
} 
consequencialismo se aproxima do polo utilitarista, ainda que alguns célebres defensores do dessa linha não se vejam como utilitaristas ${ }^{24}$.

Richard Posner afirma que o utilitarismo é uma espécie de consequencialismo ${ }^{25}$, na medida em que, na perspectiva utilitarista, o que está em jogo é justamente a avaliação das consequências de um ato, decisão ou medida a partir do critério de maximização do prazer e minimização da dor ${ }^{26}$. É a ética da burguesia industrial do século XIX ${ }^{27}$.

Seja como for, o consequencialismo difere, portanto, de aplicações da Teoria dos Princípios ${ }^{28}$ enquanto standards que apontem para situações ideais, mandados de otimização, conforme esclarece Virgílio Afonso da Silva, a partir de sua leitura de Robert Alexy ${ }^{29}$. Princípios, na dogmática alemã, são razões para instruções (Gründe für Weisungen ${ }^{30}$. Apontariam, ex ante, para determinada decisão ideal.

A avaliação filosófico-moral consequencialista opera ex post, uma vez que leva em consideração as consequências do ato. Não cria, portanto, parâmetros de conduta ideal a serem seguidos pelo agente tomador de decisão. O utilitarismo pode ser enxergado, assim, como um

corretas, sejam elas boas ou não". (JOHNSTON, David. Breve história da justiça. São Paulo: WWF Martins Fontes, 2018, p. 1-2)

${ }^{24}$ É o caso, por exemplo, de Richard Posner que em "Law, pragmatism and democracy" afirma que sua teoria da adjudicação - o legal consequentialism ou everyday pragmatism - não é propriamente um consequencialismo, este sendo, segundo o autor, "the set of philosophical doctrines (most prominently utilitarianism) that evaluate actions by the value of their consequences: the best action is the one with the best consequences". (POSNER, Richard A. Law, Pragmatism, and Democracy. [S. 1.]: Harvard University Press, 2005, p. 60)

25 "The dominant brand of consequentialism is utilitarianism, which shares some features with pragmatism but is certainly distinct from it. It is one thing to care about consequences, including consequences for utility (welfare), and another to be committed to a strategy of maximizing some class of consequences, a commitment that, as the large critical literature on utilitarianism attests, can lead to just the kind of dogmatic absurdities that pragmatists are determined to avoid" (Ibidem, p. 65)

26 "Benthamism rested on a basis of psychological hedonism, the theory that every human being seeks by nature to attain pleasure and avoid pain. This was not, of course, a novel doctrine. It had been propounded in the ancient world, notably by Epicurus, while in the eighteenth century it was defended by, for example, Helvitius in France and Hartley and Tucker in England. But though Bentham was not the inventor of the theory, he gave a memorable statement of it. «Nature has placed mankind under the governance of two sovereign masters, pain and pleasure... They govern us in all we do, in all we say, in all we think: every effort we can make to throw off our subjection will serve but to demonstrate and confirm it. In words a man may pretend to abjure their empire, but in reality he will remain subject to it all the while»". (COPLESTON, Frederick Charles. A History of Philosophy. [S. 1.]: Newman Press, 1964. v. 8, p. 8) O princípio utilitarista é enunciado da seguinte forma: "[i]f we make these assumptions and pass over the difficulties inherent in any hedonistic ethics, we can then say that right actions are those which tend to increase the sum total of pleasure while wrong actions are those which tend to diminish it, and that we ought to do what is right and not do what is wrong. We thus arrive at the principle of utility, also called the greatest happiness principle. This «states the greatest happiness of all those whose interest is in question, as being the right and proper, and only right and proper and universally desirable, end of human action»". (Ibidem, p. 9-10)

${ }^{27}$ Cf. MARÍAS, Julián. História da Filosofia. São Paulo: Martins Fontes, 2004, p. 394 e segs.

${ }^{28}$ Na perspectiva de Ronald Dworkin: "[r]aciocinar em termos jurídicos significa aplicar a problemas jurídicos específicos, como os que descrevi, uma ampla rede de princípios de natureza jurídica ou de moralidade política" (DWORKIN, Ronald. A justiça de toga. trad. Jefferson Luiz Camargo. São Paulo: WMF Martins Fontes, 2010, p. 72).

${ }^{29}$ SILVA, Virgílio Afonso da. O proporcional e o razoável. Revista dos Tribunais, n. 798, p. 23-50, 2002.

${ }^{30}$ RESSING, Maximilian. Prinzipien als Normen mit zwei Geltungsebenen: zur Untersheidung von Regeln und Prinzipien. Archiv für Rechts und Sozialphilosophie, v. 95, n. 1, p. 28-48, 2009. 
consequencialismo especializado, na medida em que traz um critério específico para avaliação de determinada conduta ${ }^{31}$.

Avalia-se, apenas, a consequência da decisão tomada, a partir da ótica de um observador externo, capaz de enxergar as repercussões para além das partes envolvidas.

Quando trazemos o consequencialismo para o âmbito do Direito, importante diferençar aquilo que seriam as consequências jurídicas das consequências reais. Jurídicas são as consequências relativas às proposições jurídicas, que são alcançadas na medida em que determinados prérequisitos são cumpridos.

Diferente é o caso das consequências reais, que são as consequências da aplicação do Direito, no mundo real. Tais consequências podem ser subdivididas em consequências reais de nível micro e consequências reais de nível macro. As de nível micro dizem respeito às partes relativas a determinada relação jurídica; ao passo que as macro são aquelas consequências que repercutem na sociedade como um todo ${ }^{32}$.

O consequencialismo é uma filosofia moral. Seu objeto diz respeito à moralidade. Seu reino é a discussão filosófica acerca da natureza da moral. Trata-se de definir o valor de determinada conduta a partir do valor de suas consequências. Ter em mente essa observação será útil para diferenciá-lo do pragmatismo, o qual passamos a caracterizar.

\subsection{Pragmatismo}

Pragmatismo é uma tradição filosófica segundo a qual palavras e pensamentos devem ser considerados como instrumentos para predição; solução de problemas; e ações, rejeitando a ideia de que a função do pensamento seja descrever, representar ou refletir a realidade.

A tradição pragmática afirma que uma série de tópicos inerentes à consideração filosófica, dentre os quais a natureza do conhecimento, a linguagem, conceitos, significados, crenças e ciência, serão mais bem compreendidos nos termos de seu uso prático e de seu sucesso. Em poucas palavras, uma coisa é o que se faz com ela na prática; os conceitos não revelam as essências das coisas, mas o que se pretende fazer com elas.

O pragmatismo se originou na segunda metade do séc. XIX, nos Estados Unidos, através da obra de autores como Charles Sanders Peirce; William James; e John Dewey, que formavam o chamado Metaphysics Club.

\footnotetext{
${ }^{31}$ HAUSMAN, Daniel; MCPHERSON, Michael. Utilitarianism and Consequentialism. In: Economic Analysis, Moral Philosophy and Public Policy, 2a ed., pp. 99-117. Cambridge: Cambridge University Press, 2006. doi:10.1017/CBO9780511754289.010.

${ }^{32}$ MATHIS, Klaus. Consequentialism in Law. In: Efficiency, Sustainability, and Justice to Future Generations, 3 Law and Philosophy Library, 1998.
} 
Peirce desenvolveu aquilo que ficou posteriormente conhecido como a máxima pragmática, em seu texto How to make our Ideas Clear, incluída dentro de uma discussão hipotética entre católicos e protestantes acerca da natureza do sacramento da Eucaristia e da doutrina da Transubstanciação ${ }^{33}$.

William James, em uma série de palestras realizadas entre 1906-1907, descreveu aquilo que seria o método pragmático ${ }^{34}$ como sendo o método para resolver disputas metafísicas que, de outra forma, seriam tidas como intermináveis. Discussões como "seria esse mundo um dentre vários?"; "somos livres ou pré-destinados?"; "materiais ou espirituais?" seriam interpretadas a partir das respectivas consequências práticas. Note-se que o pragmatismo possui uma dimensão iconoclástica em relação ao próprio discurso da filosófica metafísica, propondo-se como uma espécie de ponto final em relação a discussões antes intermináveis. A aplicação da metodologia pragmática se põe, portanto, contrária a uma investigação filosófica propensa a discussões bizantinas ${ }^{35}$. A menção à práxis serviria como norte para a solução da celeuma.

Ao pragmatismo são atribuídas três grandes características: antifundacionalismo; consequencialismo; e contextualismo. Pogrebinschi desenvolve esses temas através da seguinte síntese $^{36}$ : (i) o antifundacionalismo consiste em uma postura de rejeição a abstrações metafísicas, categorias transcendentais imutáveis, seria a recusa à ideia de certeza e imutabilidade inerente aos conceitos filosóficos tradicionais acerca da verdade e da realidade; (ii) o consequencialismo consiste na avaliação de atos ou teorias a partir de suas consequências; e (iii) o contextualismo consiste na ideia de que a investigação filosófica deveria estar atenta ao contexto no qual o objeto investigado está inserido.

Stanley Fish centra suas atenções na distinção entre fundacionalismo e antifundacionalismo:

[b]y foundationalism I mean any attempt to ground inquiry and communication in something more firm and stable than mere belief or unexamined practice. The foundationalist strategy is first to identify that ground and then so to order our activities that they become anchored to it and are thereby rendered objective and principled. (...)

\footnotetext{
${ }^{33}$ PEIRCE, Charles Sanders. How to make our Ideas clear. Popular Science Monthly, v. 12, p. 286-302, jan. 1878, p. 293.

${ }^{34}$ JAMES, William. Pragmatism: a new name for some old ways of thinking. Cambridge: Cambridge University Press, 2014

${ }^{35} \mathrm{O}$ que está em jogo, na perspectiva pragmatista, é a resolução de problemas reais e concretos que afligem a sociedade. Em outras palavras, o que importa é ação: as essências das coisas são aquilo que fazemos com elas. Do ponto de vista do direito, o pragmatismo, de acordo com Ronald Dworkin - que é uma voz crítica a esse tipo de pensamento - considera que "qualquer pessoa com poder político deve usar esse poder para tentar tornar as coisas melhores de qualquer maneira possível, dada sua posição institucional e seu grau de poder" (DWORKIN, Ronald. A justiça de toga. trad. Jefferson Luiz Camargo. São Paulo: WMF Martins Fontes, 2010, p. 35). Nesse sentido, toda discussão teórica, metafísica ou não, é inútil, na medida em que não nos leva à solução de problemas práticos e concretos.

${ }^{36}$ POGREBINSCHI, Thamy. Será o neopragmatismo pragmatista? Interpelando Richard Rorty. Novos estud. CEBRAP, São Paulo , n. 74, p. 125-138, Mar. $2006 . \quad$ Disponível em: <http://www.scielo.br/scielo.php?script=sci_arttext\&pid=S0101-33002006000100008\&lng=en\&nrm=iso>. Acesso em 28 Jan. 2021. http://dx.doi.org/10.1590/S0101-33002006000100008.
} 
Antifoundationalism teaches that questions of fact, truth, correctness, validity, and clarity can neither be posed nor answered in reference to some extracontextual, ahistorical, nonsituational reality, or rule, or law, or value; rather, antifoundationalism asserts, all of these matters are intelligible and debatable only within the precincts of the contexts or situations or paradigms or communities that give them their local and changeable shape. It is not just that antifoundationalism replaces the components of the foundationalist worldpicture with other components; instead, it denies to those components ${ }^{37}$. (FISH, 1989, p. 342-343)

O pragmatismo, como já dito, abrange uma série de tópicos da discussão filosófica. Nos interessa, contudo, o pragmatismo jurídico. Como se dá a relação entre o pragmatismo filosófico e o pragmatismo jurídico?

A interação entre o Direito e a filosofia pragmática se deu, inclusive, nas fases iniciais do movimento, no chamado The Metaphysical Club, que reunia, além dos citados Dewey; James; e Peirce, o então futuro juiz da Suprema Corte Oliver Wendell Holmes $\mathrm{Jr}^{38}$.

Alerta-se, contudo, que o pragmatismo jurídico não deve ser interpretado como uma mera aplicação do pragmatismo filosófico à realidade do Direito. O pragmatismo jurídico é compreendido como uma teoria normativa do processo decisório empreendido por agentes do Direito (majoritariamente juízes, mas não apenas).

Acerca da relação entre o pragmatismo filosófico e o pragmatismo jurídico, Arguelhes e Leal $^{39}$ sustentam que:

E o que dizer a respeito do pragmatismo jurídico? Como dito, a intuição de que existe alguma relação entre as duas coisas é certamente justificável. No entanto, seria arriscado afirmar simples e diretamente que o pragmatismo jurídico pode ser compreendido como uma aplicação da filosofia pragmatista à atividade jurisdicional. De fato, atualmente, tanto defensores quanto críticos do pragmatismo jurídico como teoria normativa da decisão judicial procuram discutilo em seus próprios termos, sem colocar no primeiro plano do debate os méritos os deméritos da filosofia pragmatista. (ARGUELHES e LEAL, 2009, p. 176)

O desenvolvimento do pragmatismo jurídico é muito associado à obra de Richard Posner, professor da Chicago Law School, e ex-juiz do sétimo circuito da Corte Federal de Apelações norteamericana, pensador igualmente importante para a Análise Econômica do Direito.

Posner possui uma série de trabalhos acerca do pragmatismo jurídico e enumera doze afirmações genéricas que são úteis para a compreensão do instituto ${ }^{40}$ :

\footnotetext{
${ }^{37}$ FISH, Stanley. Doing What Comes Naturally: Change, Rhetoric, and the Practice of Theory in Literary \& Legal Studies. [S. 1.]: Duke University Press, 1989, p. 342-343.

${ }^{38}$ MENAND, Louis. The Metaphysical Club: a Story of Ideas in America. Nova York: Farrar, Straus \& Giroux. 2001.

39 ARGUELHES, Diego Werneck; LEAL, Fernando. Pragmatismo como (meta)teoria normativa da decisão judicial: caracterização, estratégias e implicações. In: SARMENTO, Daniel (Org.). Filosofia e Teoria Constitucional Contemporânea. Rio de Janeiro: Lumen Juris, 2009, p. 171/211, p. 176.

${ }^{40}$ POSNER, Richard. Law, Pragmatism and Democracy. Cambridge, MA: Harvard University Press. 2003. P. $60-61$
} 
(i) pragmatismo jurídico não é apenas um eufemismo para decisões ad hoc particularistas. Envolve considerações sistêmicas e não apenas contempla consequências específicas para o caso examinado;

(ii) apenas em casos específicos o juiz pragmatista atribuirá peso determinante às consequências sistêmicas, contudo. Em muitos outros casos as consequências específicas do caso serão determinantes;

(iii) $\mathrm{O}$ critério derradeiro para a adjudicação pragmatista é a razoabilidade (reasonableness);

(iv) O pragmatismo jurídico não é uma forma de consequencialismo, compreendida como o conjunto de doutrinas filosóficas que avaliem a virtude das ações exclusivamente pelo valor de suas consequências;

(v) O pragmatismo jurídico volta o seu olhar para futuro, considerando a aderência às decisões passadas mais como uma necessidade do que como um dever ético;

(vi) O pragmatista jurídico crê que não há procedimentos analíticos que distinguem o raciocínio jurídico de outras formas de raciocínio prático;

(vii) O pragmatismo jurídico é empirista;

(viii) Enquanto empirista, não é hostil a todas as teorias, apenas em relação às ideias que se utilizem de morais abstratas e teorias políticas para guiar a tomada de decisão judicial;

(ix) O pragmatismo jurídico não é um suplemento do formalismo;

(x) O pragmatismo jurídico é simpático à concepção sofista e aristotélica da retórica enquanto forma de razão;

(xi) o juiz pragmático tende a favorecer argumentos específicos em detrimento de argumentos generalistas;

(xii) o pragmatismo jurídico é tanto diferente do realismo jurídico quanto dos estudos críticos do Direito (critical legal studies, abreviados como crits).

Os itens $i v$; xi; e xii merecem comentários.

Segundo Posner, o pragmatismo jurídico não seria uma forma de consequencialismo, pois a expressão mais usual do consequencialismo - o utilitarismo - em que pese coincida com o pragmatismo jurídico em certos pontos, exigiria, caso adotado, que o julgador estivesse compreendido com uma estratégia maximizadora de utilidade, unicamente, o que poderia causar absurdos dogmáticos com os quais pragmatistas jurídicas não concordariam.

O juiz pragmático, segundo o referido autor, seria tendente, como dito, a favorecer argumentos específicos em detrimento de argumentos generalistas. Seriam, assim, mais sensíveis à retórica do que adeptos de outras correntes do pensamento jurídico. Questões jurídicas difíceis, os 
hard cases, não possuiriam uma resposta certa a priori, sendo casos em que a retórica e a argumentação específica do caso concretamente examinado desempenhariam papel relevante na solução do problema.

Posner afirma que o pragmatismo filosófico seria apenas uma espécie de "atitude pragmática", caracterizada por uma pré-disposição para avaliar julgamentos e ações a partir de uma ótica que leve em consideração as consequências em detrimento de conceitos, abstrações e generalidades ${ }^{41}$. Apesar de tal descrença, o pragmatismo filosófico seria, ainda assim, uma teoria acadêmica, diferente daquilo que ele chama de pragmatismo do cotidiano (everyday pragmatism).

O pragmatismo jurídico, enquanto postura do tomador de decisão, mais deve ao pragmatismo cotidiano, bem definido pelo uso popular do termo "pragmático", significando um indivíduo prático, "pés-no-chão", descrente de utopias ${ }^{42}$, do que ao pragmatismo filosófico.

O pragmatismo jurídico olha para o Direito com o intuito de avaliar a praticidade de seus institutos. Na medida em que é empirista e avaliativo, o grande mérito do pragmatismo jurídico é a possibilidade de conferir falseabilidade às hipóteses desenvolvidas acerca da aplicação de determinado instituto do Direito, permitindo uma aplicação experimentalista.

Gustavo Binenbojm, nesse sentido, afirma que "a postura pragmática é, assim, essencialmente crítica e experimental, sempre aberta a novas possibilidades que possam falsear as hipóteses até então descritas como verdadeiras"43.

A aplicação clássica do pragmatismo jurídico diz respeito ao caso Bush v. Gore, no qual a Suprema Corte dos Estados Unidos suspendeu a realização de novas recontagens dos votos da Flórida, recontagem essa exigida por lei estadual e que reduzia a vantagem de Bush sobre Gore sucessivamente. $\mathrm{O}$ argumento pragmático lançado à mão pela Suprema Corte foi no sentido de que nova recontagem seria institucionalmente negativa e minaria a legitimidade do então recém eleito Presidente Bush ${ }^{44}$.

No contexto da discussão envolvendo essa decisão, Posner articulou, de modo claro e enfático, a visão do pragmatismo jurídico que defende:

\begin{abstract}
"Pragmatic" as an adjective for anything to do with the judicial process still causes shudders. It seems to open up vistas of judicial willfulness and subjectivity and to mock the rule of law; it seems to equate law to prudence, and thus to be Machiavellian. All that pragmatic adjudication need mean, however-all that I mean by it-is adjudication guided by a comparison of the consequences of alternative resolutions of the case rather than by an algorithm intended to lead the judges by a logical or otherwise formal process to the One Correct Decision, utilizing only the canonical materials of judicial decision making, such as
\end{abstract}

\footnotetext{
${ }^{41}$ ARGUELHES, Leal, op. cit., p. 177.

${ }^{42}$ POSNER, op. cit., p. 50.

43 BINENBOJM, Gustavo. Poder de Polícia, Ordenação, Regulação: transformações político-jurídicas, econômicas e institucionais do Direito Administrativo Ordenador. Belo Horizonte: Fórum, 2016. P. 55.

${ }^{44}$ POSNER, Richard. Bush v. Gore as Pragmatic Adjudication, in: A Badly Flawed Election: Debating Bush v. Gore, the Supreme Court, and American Democracy, Ronald Dworkin eds., 2002.
} 
statutory or constitutional text and previous judicial opinions ${ }^{45}$.(POSNER, 2001, p. 186)

Não se trata de um vale-tudo judicial, mas de um juízo de comparação de possíveis consequências alternativas de determinada adjudicação. Comparação que levará em conta, inclusive, o que Posner chama de consequências sistêmicas, ou seja, as exigências de consistência e previsibilidade do Direito, as exigências do seu passado representado por precedentes, textos legais e opiniões doutrinárias ${ }^{46}$.

A concepção de Posner, se se leva em conta a ideia de consequências sistêmicas, aproximase, em alguma medida, da de consequencialismo de regras.

Ainda no contexto do caso Bush v. Gore, pode-se colocar a questão - dita hiperpragmática por Posner - sobre se um juiz poderia - melhor dizendo: deveria - reverter o resultado de uma eleição dado o fato de que a escolha dos eleitores representaria, na perspectiva desse juiz, uma consequência desastrosa ${ }^{47}$.

${ }^{45}$ POSNER, Richard A. Breaking the Deadlock: The 2000 Election, the Constitution, and the Courts. [S. 1.]: Princeton University Press, 2001, p. 186.

${ }^{46}$ No dizer de Posner: "[s]ystemic consequences are not excluded. The pragmatic judge does not squint myopically at the consequences of the case at hand, oblivious to the possible consequences of his decision for future cases. He recognizes that the needs of the future, along with the limitations of judges' knowledge, may rule certain consequences out of consideration, such as a preference for one Presidential candidate over another" (Ibidem, $p$. 186). O pragmatismo jurídico de Posner é uma espécie de consequencialismo. Tudo gira em torno da comparação das possíveis consequências de uma determinada decisão judicial. Mas essa comparação não é cega. De modo semelhante ao que ocorre no utilitarismo, há um princípio que guia essa comparação. E esse princípio é a preservação da previsibilidade e consistência interna do Direito: o que Posner chama de "systemic consequences", isto é, as consequências que dizem respeito à integridade do sistema jurídico - precedentes judiciais, textos normativos e doutrina - relativamente à sua capacidade de servir de instrumentos de planejamento para as ações futuras dos indivíduos e sociedade. Dworkin, apesar de adversário da concepção pragmatista de Posner, faz um resumo muito acurado dessa teoria da adjudicação: "[o] juiz que é pragmatista nesse sentido cotidiano e consequencialista não despreza o precedente e a argumentação técnico-jurídica: ao contrário, ele tem consciência delas, levando em consideração tanto as consequências positivas que decorrem do respeito judicial sistemático pela argumentação e doutrina jurídicas tradicionais, que incluem estimular pessoas a planejar os assuntos de seus interesse com confiança, quanto as consequências negativas que possam decorrer do fato de um juiz ignorar a doutrina tradicional em determinadas ocasiões, o que inclui a frustração dessas expectativas e o enfraquecimento do benefício geral do respeito sistemático por elas. Mas o juiz pragmático também tem consciência dos perigos de uma deferência servil ao raciocínio jurídico ortodoxo; ele sabe que, em certas circunstâncias, pode obter resultados melhores, inclusive a longo prazo, ao chegar à decisão que resultará em algum benefício particularmente importante, ou que evitará algum risco especialmente grave, ainda que tal decisão desafie abertamente a doutrina estabelecida. Portanto, os juízes pragmáticos precisam equilibrar os benefícios a longo prazo do respeito à doutrina com os benefícios a longo prazo que, em algumas ocasiões, decorrem do fato de ignorá-la. Como afirma Posner, '[n]ão existe algoritmo para se chegar a tal equilíbrio (...). O juiz deve tentar tomar a decisão que seja razoável, depois de um exame criterioso de todas as coisas, um contexto no qual 'todas as coisas' inclui as fontes do direito e a jurisprudência clássica (...), mas também as consequências, na medida em que se possa discerni-las da decisão do caso em questão"'. (DWORKIN, Ronald. A justiça de toga. trad. Jefferson Luiz Camargo. São Paulo: WMF Martins Fontes, 2010, p. 135-136)

${ }^{47}$ A questão é interessante, pois coloca o problema de saber se as preferências político-ideológicas dos juízes podem ser levadas em conta quando da avaliação das consequências de uma possível decisão. No caso que se discute, um juiz de tendências conservadoras poderia ver com bons olhos uma decisão que favorecesse Bush, do mesmo modo que, ao contrário, um juiz de tendências liberais veria numa decisão que desse ganho de causa a Gore uma de consequências mais palatáveis. Posner afirma que "[p]ragmatic adjudication is concerned with consequences but does not in itself determine their weight or valence. It accepts that each judge will, within the bounds of permissible judicial discretion (that is, with due but not slavish regard for the rule-of-law virtues), cast 
Para que possamos evoluir é preciso, por ora, ter em mente que o pragmatismo jurídico, embora preocupado, sim, com as consequências das decisões judiciais, não é uma abordagem exclusivamente consequencialista à moda do utilitarismo. É dizer, em outras palavras, que não possui um conceito pré-determinado (o que contraria a sua vocação antifundacional) a respeito daquilo que seriam as consequências desejáveis para todo e qualquer contexto, a exemplo do que seria a utilidade para os utilitaristas.

Essa característica é importante para demonstrar que o pragmatismo não é incompatível com a Análise Econômica do Direito. O pragmatismo jurídico é permeável ao influxo de outras teorias e áreas do conhecimento - a Economia forneceria, assim, substrato para uma decisão pragmatista. A decisão pragmatista não se encerra, contudo, na mensuração das consequências através de critérios econômicos.

\subsection{Análise Econômica do Direito}

Surgida nos Estados Unidos de fins dos anos 1950 a 1960, a Análise Econômica do Direito (Law and Economics), abreviada como AED, nada mais é do que a aplicação dos pressupostos da Teoria Econômica para a análise de institutos do Direito, seja através de um viés descritivo, quanto através de um viés normativo.

A origem da Análise Econômica do Direito está relacionada ao Realismo Jurídico NorteAmericano, e é antagonizada por outro movimento oriundo do Realismo, o Critical Legal Studies - CLS. A AED e a CLS possuem em comum a "proposição de modos alternativos de enquadrar o fenômeno jurídico". ${ }^{48}$ Os crits, como são apelidados os adeptos do CLS, são marcados por um compromisso político de denunciar o Direito como uma forma de controle autoritário da sociedade. A AED é pretensamente neutra politicamente, embora acusada pelos crits como fomentadores do neoliberalismo ${ }^{49}$.

\footnotetext{
his vote on the basis of personal values, temperament, unique life experiences, and ideology" (POSNER, Richard. Law, Pragmatism and Democracy. Cambridge, MA: Harvard University Press, 2003, p. 333). Mais uma vez as consequências sistêmicas - aqui um certo apreço pelas qualidades da rule of law - funcionam como um limite, como uma barreira final às considerações consequencialistas. Preferências pessoais, e mesmo visões políticoideológicas, dos juízes podem - e certamente o farão - influenciar suas decisões e, mais do que isso, seus cálculos de consequências. Isso não é um problema desde que não coloque em xeque a estabilidade e previsibilidade que se espera do ordenamento jurídico: as consequências sistêmicas funcionam como uma chave de abóbada do consequencialismo de Posner.

${ }^{48}$ ARAÚJO, Thiago Cardoso. Análise Econômica do Direito no Brasil: uma leitura à luz da Teoria dos Sistemas. Rio de Janeiro: Lumen Juris, 2017, p. 282.

${ }^{49}$ ZANATTA, Rafael. Desmistificando a Law \& Economics: a Receptividade da Disciplina Direito e Economia no Brasil. Revista dos Estudantes de Direito da UNB (REDUnB), v. 10, 2012.
} 
A Análise Econômica se reveste de uma pretensão cientificista. Definir o que é ciência em detrimento daquilo que não é considerado ciência consiste no chamado problema da demarcação $0^{50}$, não sendo um problema de simples solução. A aplicação de forma não problemática do método científico pode, contudo, servir como critério de separação.

O Direito, ao incorporar paradigmas teóricos da Economia, se robustece enquanto ciência, na medida em que suas conclusões teóricas passam a ser testáveis a partir de métodos mais exatos ${ }^{51}$.

A Teoria Econômica possibilita a realização de previsões de comportamentos, isto é, de que forma os agentes reagirão a determinadas leis, p.e., bem como avaliam a eficiência econômica de institutos e a distribuição de riqueza por eles gerada ${ }^{52}$.

O insight principal que a economia provê para a análise jurídica seria a ideia de que pessoas respondem a incentivos, uma afirmação generalista da teoria dos preços. A lei serve para estimular condutas desejáveis e desestimular condutas indesejáveis, encorajando ou desencorajando a produção de recursos sociais e a eficiente alocação de recursos. A AED é, em sua raiz, uma teoria comportamentalista ${ }^{53}$.

Os primeiros scholars da AED importaram da economia uma série de presunções acerca de como as pessoas respondem a incentivos, conhecido, genericamente, como rational choice theory. Tal teoria não é, contudo, cerrada, flutuando entre dois extremos de um espectro: thin e thick, que serão desenvolvidos agora.

As concepções thin, finas, entendem que o comportamento humano é racional a partir da fixação de critérios genéricos de racionalidade, ao passo que as concepções thick, grossas, determinam critérios mais específicos para que a racionalidade de determinada conduta seja $\operatorname{atestada}^{54}$

A AED nada mais é, portanto, do que a utilização de pressupostos da teoria econômica para tanto justificar institutos do ordenamento jurídico quanto para avaliá-los. Não se trata, assim, de

\footnotetext{
${ }^{50}$ THORNTON, Stephen. "Karl Popper". The Stanford Encyclopedia of Philosophy (Spring 2021 Edition), Edward N. Zalta (ed.), no prelo. Disponível em: <https://plato.stanford.edu/archives/spr2021/entries/popper/>. Acesso em 18 de fev. de 2021.

${ }^{51}$ Suprindo, assim, o elemento faltante para a melhor caracterização do Direito enquanto ciência, cf. ULEN, Thomas. A Nobel Prize in Legal Science: Theory, Empirical Work, and the Scientific Method in the Study of Law. University of Illinois Law Review, v. 2002, n. 4, pp. 875-920, pág. 893: I claim that there are already some elements of the scientific method in the study of law but that there are some important defining elements that are missing - namely, a wiedespread and commonly accepted theoretical core or paradigm and accepted standards and methods of empirical or experimental validation.

${ }^{52}$ COOTER, Robert; Ulen, Thomas. Law \& Economics - 6a ed. Essex: Pearson, 2014. Para uma perspectiva crítica da capacidade preditiva das ciências sociais em geral, e inclusive dos métodos estatístico-matemáticos, v. Elster, Jon.Excessive Ambitions, Capitalism and Society: v.. 4, n. 2Iss. 2, artigo 1, pp. 1-33, 2009. Disponível em: https://papers.ssrn.com/sol3/papers.cfm?abstract_id=2209382\#. Acesso em 19 de mar. De 2021.DOI: 10.2202/1932-0213.1055.

${ }^{53}$ KOROBKIN, Russel; ULEN, Thomas. Law and Behavioral Science: Removing the Rationality Assumption from Law and Economics. California Law Review, vol. 88, n. 4, p. 1051-1144. 2000.

${ }^{54}$ Idem.
} 
uma teoria normativa da decisão judicial, por exemplo, que defenda a utilização de uma espécie de consequencialismo economicista como ferramenta de decisão judicial.

Dilemas analisados pela AED podem ser formulados a partir da seguinte estrutura: "a atual legislação de patentes gera incentivos ou restrições à inovação tecnológica?”; “a possibilidade de a Administração Pública extinguir unilateralmente um contrato administrativo torna as contratações públicas mais ou menos eficientes?"; "a responsabilidade civil objetiva em contratos de consumo gera mais ou menos riqueza" e assim por diante.

Há, assim, uma Análise Econômica da Propriedade ${ }^{55}$, da Responsabilidade Civil ${ }^{56}$, dos Contratos $^{57}$ etc.

A Análise Econômica do Direito possui textos seminais, merecendo destaque The Problem of Social Cost, de Ronald Coase ${ }^{58}$, do qual deriva o chamado Teorema de Coase, segundo o qual em um mundo os custos de transação sejam iguais a zero, a mudança de uma regra jurídica de responsabilidade não teria efeito algum sobre a alocação de recursos ${ }^{59}$.

vA AED analisa os institutos e a prática do Direito à luz da eficiência econômica. A eficiência é um conceito chave da Economia, e pode ser trabalhado a partir de duas perspectivas: (i) Eficiência de Pareto; (ii) Eficiência Kaldor-Hicks.

Segundo o modelo de Eficiência de Pareto, determinada alteração alocativa será eficiente se melhorar a situação de um indivíduo, ao menos, sem, contudo, piorar a de nenhum. O conceito de eficiência assumido por Kaldor-Hicks, diversamente, entende que determinada alteração alocativa será eficiente se possibilitar que os ganhos dos ganhadores compense as perdas dos perdedores basta, note-se, que a alteração possibilite a compensação, não necessitando que, de fato, compense $^{60}$.

A Análise Econômica do Direito pode ser dividida, epistemologicamente, em dois níveis: AED positiva e AED normativa. O nível positivo, também chamado descritivo, afirma que os

\footnotetext{
${ }^{55}$ DEMSETZ, Harold. Toward a Theory of Property Rights. The American Economic Review, v. 57, n. 2, Papers and Proceedings of the Seventy-ninth Annual Meeting of the American Economic Association. p. 347-359. 1967. Disponível em: <https://www.jstor.org/stable/1821637?seq=1\#metadata_info_tab_contents>. Acesso em $29 \mathrm{de}$ janeiro de 2021.

${ }^{56}$ SCHWARTZ, Gary T. Reality in the economic analysis of tort law: does tort law really deter. UCLA Law Review, v. 42, p. 377, 1994. Disponível em: <https://heinonline.org/HOL/Page?public=true\&handle= hein.journals/uclalr42\&div=17\&start_page $=377 \&$ collection $=$ journals \&set_as_cursor $=2 \&$ men_tab $=$ srchresults $>$. Acesso em: 29 de janeiro de 2021.

${ }^{57}$ SHAVELL, Steven. Specific Performance Versus Damages for Breach of Contract: An Economic Analysis. Texas Law Review, v. 84, n. 4, p. 831. 2006. Disponível em: <http://www.law.harvard.edu/faculty/shavell/pdf/ Shavell-SpecPerf-06.pdf>. Acesso em: 29 de janeiro de 2021.

${ }^{58}$ COASE, Ronald. The problem of social cost. Journal of Law and Economics, v. 3, p. 1-44, out. de 1960.

${ }^{59}$ ELLICKSON, Robert. Of Coase and cattle: a dispute resolution among neighbors in Shasta Count. Stanford Law Review, n. 38, p. 623-687, 1986. Disponível em: <https://www.jstor.org/stable/1228561?seq=1\#metadata _info_tab_contents>. Acesso em: 29 de janeiro de 2021.

${ }^{60}$ POSNER, Richard. The Value of Wealth: a comment on Dwokin and Kronman. The Journal of Legal Studies, v. 9, n. 2, pp. 243-252, mar. 1980.
} 
conceitos da microeconomia são de valia para o estudo do fenômeno jurídico, utilizando-se de uma capacidade explicativa oferecida pela teoria econômica.

O nível normativo, também chamado prescritivo, avalia institutos do Direito à luz da eficiência econômica. Questiona, inclusive, se o conceito de justiça deveria ser identificado com a eficiência ${ }^{61}$.

A Análise Econômica do Direito é, assim, tanto uma ciência explicativa quanto uma metodologia de avaliação ${ }^{62}$, metodologia essa que avalia as consequências econômicas do Direito.

A AED normativa, na medida em que avalia como eficiente determinada consequência de uma aplicação do Direito, nada mais é do que uma forma de consequencialismo de regras ${ }^{63}$, tendo em vista que este avalia as consequências de determinado ato a partir de regras estabelecidas $e x$ ante. Trata-se de um consequencialismo fundado na Teoria da Eficiência.

A evolução da AED enquanto objeto de estudo se deu no contexto da common law, no qual incumbe, em regra, ao juiz dizer o direito. Esse aspecto criador do Direito traz à rotina da decisão judicial questionamentos como "qual é a função do Direito?", e mesmo uma preocupação maior com as consequências de determinada decisão pois, diferentemente dos países de tradição romana, o juiz não julga - em regra - com esteio em um direito codificado - o que faz com que acabe atraindo os ônus de uma decisão ruim para si e não para um legislador que tenha vislumbrado, em abstrato, a solução para o futuro caso concreto.

\section{Consequencialismo, Pragmatismo, Análise Econômica do Direito e o Brasil}

O consequencialismo, o pragmatismo e a Análise Econômica adentraram o Brasil em um cenário em que a expansão da Teoria dos Princípios chegou a um ponto de inflexão, no qual se observa a utilização da principiologia - sobretudo constitucional - como forma de fundamentar um particularismo decisório de magistrado de todos os graus.

A nova redação à LINDB se mostra, assim, como uma tentativa legislativa de reagir a uma forma de aplicação de princípios que foi chamada por Carlos Ari Sundfeld como preguiça ${ }^{64}$.

61 SALAMA, Bruno. “O que é Direito e Economia?”. Direito UNIFACS, n. 160, 2013. Disponível em: < https://revistas.unifacs.br/index.php/redu/article/view/2793/2033>. Acesso em 3 de março de 2021.

62 GICO JUNIOR, Ivo Teixeira. Notas sobre a Análise Econômica do Direito e Epistemologia do Direito. Direito UNIFACS, n. 160, 2013. Disponível em: < https://revistas.unifacs.br/index.php/redu/article/view/2794>. Acesso em 3 de março de 2021.

${ }^{63}$ CSERNE, Péter. Consequence-Based Arguments in Legal Reasoning: A Jurisprudential Preface to Law and Economics. In: Mathis K. (eds) Efficiency, Sustainability, and Justice to Future Generations. Law and Philosophy Library, vol 98. Springer, Dordrecht, 2012.

${ }^{64}$ SUNDFELD, Carlos Ari. Princípio é preguiça? In: Ronaldo Porto Macedo Jr. e Catariana Barbieri (org). Direito e interpretação - racionalidades e instituições. São Paulo: Saraiva, 2011, pp. 287-305. 
A incorporação de novas metodologias - mais práticas - se dá, assim, em um contexto de oposição. Se o consequencialismo, enquanto filosofia, é oposto à deontologia, não é surpreendente que, no Brasil, haja esse antagonismo em relação a um padrão decisório que enfatize consequências práticas de decisões quando o juiz lança mão de argumentos principiológicos, cuja natureza deontológica parece ser evidente ${ }^{65}$.

O giro pragmático ${ }^{66}$, quando aliado a uma metodologia como a Análise Econômica, pode mitigar as consequências ruins de uma jurisdição decisionista, a partir de uma exigência de arcar com o ônus argumentativo das consequências práticas de uma aplicação de princípios abstratos. O Direito passaria a ser, assim, mais exato e previsível.

A Análise Econômica do Direito, em uma versão normativa, pode se desenvolver, portanto, como uma teoria normativa acerca da decisão judicial ${ }^{67}$, inserindo a atividade jurisdicional no sistema econômico, demonstrando que as decisões judiciais, além de terem consequências, têm consequências econômicas.

Se esses são os pontos otimistas referentes à incorporação de teorias consequencialistas no Brasil, paira o medo de que surja um consequencialismo à brasileira, segundo o qual as "consequências práticas" se tornam um mero argumento teórico - tal qual à dignidade da pessoa humana - de baixa densidade semântica, apto a fundamentar qualquer particularismo decisório, ou mesmo voluntarista ${ }^{68}$.

Esse risco é maximizado, sobretudo, em um contexto de um cada vez maior protagonismo judicial.

Se hoje a razoabilidade é a palavra coringa, amanhã as "consequências práticas" ou a "eficiência econômica" podem vir a substitui-la. A utilização dos termos consequencialista e pragmatismo não é estranha à jurisprudência do Supremo, conforme podemos observar pelos exemplos a seguir enumerados:

\footnotetext{
${ }^{65}$ Nesse sentido, ver artigo 20, LINDB: Art. 20. Nas esferas administrativa, controladora e judicial, não se decidirá com base em valores jurídicos abstratos sem que sejam consideradas as consequências práticas da decisão.

${ }^{66}$ Binenbojm, op. cit.

${ }^{67}$ MARTINS, Daniela Berwanger; PAZETO, Matheus Lolli. Breves linhas sobre a inclusão da Análise Econômica do Direito na prolação de uma decisão judicial. In: Reflexões sobre Direito e Economia (Armando Castelar Pinheiro et al. org). pp. 145-164. Rio de Janeiro: FGV Direito Rio, 2020.

${ }^{68}$ Leal nota o paradoxo de que a importação de teorias, na busca a dar mais certeza ao processo decisório judicial, muitas vezes acaba por aumentar a incerteza ao fornecer novos instrumentos teóricos para o decisionismo: Maiores esforços de determinação não necessariamente levam a maior limitação da discricionariedade. Ao contrário, como afirmado, podem apenas tornar o processo decisório mais incerto. Tome-se, como exemplo, a pluralidade de métodos disponíveis para orientar a interpretação constitucional no país e a dificuldade cada vez maior de antecipação de resultados e dos caminhos da fundamentação de decisões no Supremo Tribunal Federal. A tentativa de "controlar" a interpretação constitucional por meio de métodos e teorias decisórias que apelam para elementos contrafactuais ou prescrições vagas, em vez de aumentar a previsibilidade dos resultados, permite, na verdade, que fundamentos teóricos muito diferentes possam ser livremente selecionados para justificar qualquer decisão.

(LEAL, Fernando. Regulando a incerteza: a construção de modelos decisórios e os riscos do paradoxo da determinação. Revista de investigações constitucionais, Curitiba, v. 3, n. 3, p. 219, set./ dez. 2016.)
} 
A Ação Originária n. 1.773, de relatoria do Min. Fux ${ }^{69}$, afirma que:

A partir dessa visão, o pragmatismo revoluciona o modo como se problematizam as funções institucionais dos magistrados, bem como a relação entre prática judicial e filosofia deontológica. Cada vez mais, Cortes constitucionais têm adotado explicitamente o discurso consequencial para resolver conflitos, especialmente em contextos de crise política e econômica. Antes um ideário distante, o pragmatismo tornou-se common place na prática adjudicativa. (BRASIL, 2018)

A menção ao pragmatismo se dá, aqui, em oposição a ideias deontológicas, associando-o em demasia, porém ao consequencialismo, ao citar um "discurso consequencial". De fato, uma visão superficial pode enxergar relação de sobreposição entre o pragmatismo (jurídico) e o consequencialismo, lembrando, contudo, que o consequencialismo é uma filosofia moral que julga a moralidade de atos de acordo com suas consequências práticas. O pragmatismo, assim, é consequencialista, mas há outras formas de consequencialismo, como o utilitarismo (exemplo de consequencialismo de regras, conforme já mencionado).

Outro caso que evoca tais ideais, igualmente de relatoria do Min. Fux, é o RE 1.083.955 ${ }^{70}$, no qual se afirma que: "Os controles regulatórios, à luz do consequencialismo, são comumente dinâmicos e imprevisíveis". A ideia, aqui, é mencionar a mutabilidade dos controles regulatórios em razão do que seria uma perspectiva consequencialista, pautada nas consequências de determinada regulação. A menção ao consequencialismo, contudo, parece se dar de forma retórica, evocando as hoje habituais menções a figuras como a razoabilidade e proporcionalidade.

Outra decisão interessante, e que merece, inclusive, maior destaque, diz respeito à ADI 5543/DF, de relatoria do Min. Fachin. A referida ação de controle concentrado de constitucionalidade se insurge contra normas que vedam a doação de sangue por parte de homossexuais. Se uma das tônicas deste artigo é a preocupação com a má-importação de teorias estrangeiras, há, nessa ADI, uma espécie de espantalho feito em relação ao consequencialismo, afirmando que a discriminação contra a doação de sangue de homens homossexuais se daria em razão de uma "interpretação consequencialista desmedida". Essa visão de consequencialismo preocupa tanto quanto aquela que associa o positivismo jurídico ao nazismo ${ }^{71}$.

Apesar de uma certa despreocupação nas menções ao consequencialismo e ao pragmatismo, convém tolher o pessimismo: se a razoabilidade e a proporcionalidade podem facilmente ser evocadas retoricamente como rotas de escape no processo de tomada de decisão, elas o são pela dificuldade em serem falseadas.

\footnotetext{
${ }^{69}$ Ação Originária 1.773, Supremo Tribunal Federal, Rel. Min. Luiz Fux, Decisão Monocrática de 26/11/2018.

${ }^{70}$ RE 1083955 AgR, Relator(a): LUIZ FUX, Primeira Turma, julgado em 28/05/2019, publicado em 07/06/2019.

${ }^{71}$ Para aprofundamento na discussão, v. BORGES VALADÃO, Rodrigo. A luta contra a teoria pura do direito na República de Weimar e o caminho para o nacional-socialismo. Revista Eletrônica da PGE-RJ, v. 3, n. 3, 30 dez. 2020.
} 
O mesmo não se pode dizer, todavia, da menção às consequências práticas de determinada decisão, que podem ser demonstradas empiricamente. É ligar, assim, o plano normativo à realidade $^{72}$, respondendo à pergunta: "qual a consequência prática de determinado instituto jurídico?", garantindo ao Direito, assim, aptidão para alterar a realidade.

Se a antropofagia é uma das marcas da cultura brasileira - no que é louvável, pois a postura de receptividade a novas teorias sempre enriquece o debate - por vezes é necessária uma antropofagia reversa, na qual se busca reconstruir aquilo que foi consumido à sua forma anterior. Esse foi o objetivo deste artigo: delimitar os conceitos de consequencialismo, pragmatismo e Análise Econômica do Direito antes que os processos digestórios antropofágicos, aliados à repetição acadêmica, o tornem impossível.

\section{Conclusão}

O presente artigo identificou a existência, no Brasil, de uma tendência de importação e transformação de teorias estrangeiras. Não apenas tais teorias se transformam como acabam, por vezes, se amalgamando.

Autores do Direito brasileiro identificam na jurisprudência brasileira, inclusive, um histórico de uso não tão rigoroso de teorias importadas - é o exemplo da Teorias dos Princípios, que é utilizada, de forma retórica, a fundamentar particularismos judiciais.

Propusemos, assim, que há uma nova leva de importação de teorias, que contempla o consequencialismo, o pragmatismo e a Análise Econômica do Direito. A preocupação levantada foi no sentido de uma possível utilização incorreta de tais teorias.

A hipótese deste artigo é de que, se ideias são mal importadas, é importante a adequada conceituação e diferenciação dos conceitos. Dessa forma, procuramos expor o consequencialismo, o pragmatismo e a Análise Econômica do Direito nos termos em que foram tratados originalmente.

Para tal, explicamos os conceitos; identificamos as semelhanças; e delineamos a linha de separação conceitual.

O consequencialismo seria, assim, uma filosofia moral segundo a qual a moralidade de determinada ação é avaliada a partir das suas consequências. Há duas espécies de consequencialismo: o consequencialismo de atos, e o consequencialismo de regras. $\mathrm{O}$ primeiro avalia o ato a partir de suas consequências, tendo apenas o ato como referencial; o segundo avalia $\mathrm{o}$ ato de acordo com a aderência a um conjunto de regras previamente determinado.

\footnotetext{
${ }^{72}$ PARGLENDER, Mariana, SALAMA, Bruno. Direito e consequência no Brasil: em busca de um discurso sobre o método. Revista de Direito Administrativo, v. 262, p. 95-144, jan./abr. 2013.
} 
O pragmatismo, enquanto corrente filosófica, entende que as palavras e pensamentos devem ser considerados como instrumentos para predição; solução de problemas; e ações, rejeitando a ideia de que a função do pensamento seja descrever, representar ou refletir a realidade.

O pragmatismo jurídico, a seu turno, é compreendido como uma teoria normativa do processo decisório empreendido por agentes do Direito.

A Análise Econômica do Direito, por fim, cuida da aplicação dos pressupostos da Teoria Econômica para a análise de institutos do Direito, seja através de um viés descritivo, quanto através de um viés normativo.

Há semelhanças especialmente entre o consequencialismo e o pragmatismo. Uma das três características associadas ao pragmatismo é, inclusive, o consequencialismo. A Análise Econômica do Direito, a seu turno, pode ser compreendida como uma espécie de consequencialismo de regras pautado, especialmente em sua vertente normativa, por uma teoria de eficiência econômica ${ }^{73}$.

Se o artigo demonstrou que tais conceitos possuem uma zona de tangência comum, não se pode dizer, contudo, que sejam sinônimos e nem que possam ser utilizadas de forma fungível. É preciso, pois, identificar a correta abrangência conceitual de cada uma das teorias, de modo a evitar a aplicação incorreta, que em nada contribui para a disseminação de tais teorias e abordagens. Ao contrário: ao criar um aparato intelectual de fronteiras pouco definidas, cria-se um espantalho, passível de denúncia e crítica ${ }^{74}$.

\footnotetext{
${ }^{73}$ Sobre as dimensões teóricas da Análise Econômica do Direito, Ulen afirma que: "Let me begin with an argument about theory. There seems to be much more of it in legal scholarship than was the case twenty years ago. Probably the most obvious culprit in this regard is law and economics. Whatever else they have done, scholars working from that perspective have assiduously explored the legal system to see the extent to which law is efficient. They have articulated a comprehensive theory - both positive and normative - that asserts that, for example, the rules and standards of property law should (and largely do) foster the efficient use of society's scarce resources, that contract law should (and largely does) efficiently lower the transaction costs of forming and completing consensual agreements, that tort law should (and largely does) efficiently minimize the social costs of accidents, and that po argely do) efficiently choose between settlement and litigation.116 These same tools-microeconomic analysis of legal decision making on the assumption that everyone involved is a rational actor-has also been extended into the areas of public law, such as corporate law,117 criminal law,118 bankruptcy,119 and family law." (ULEN, Thomas. A Nobel Prize in Legal Science: Theory, Empirical Work, and the Scientific Method in the Study of Law. University of Illinois Law Review, v. 2002, n. 4, pp. 875-920, pág. 909).

${ }^{74}$ Essas ideias e conceitos mal definidos e mal delimitados tornam-se alvos fáceis de críticas. Críticas essas que, justamente por mirarem, não a melhor versão dessas ideias, mas a versão abrasileirada, tendem a se multiplicar e a se consolidar, como se o que tivesse ocorrido fosse de fato uma refutação em regra. Na verdade, tratou-se apenas da refutação a um espantalho que pouco ou nada tem que ver com a ideia na sua versão original. Exemplo típico desse espantalho é o que costuma ocorrer com as críticas ao positivismo. As críticas brasileiras, salvo exceções, tratam o positivismo como um tipo de legalismo radical desacreditado mundo afora. Sob essa luz, é relativamente fácil criticar o positivismo. O problema é que não se trata, na espécie, de positivismo, mas apenas de um espantalho, de uma mera sombra, pouco nítida, do positivismo tal como apresentado pelos seus principais expoentes, tais como, por exemplo, H. L. A. Hart, John Gardner e Joseph Raz. O mesmo vale para as ideias tratadas neste artigo: se se trata de criticar o consequencialismo, o pragmatismo ou a análise econômica do direito, é preciso, antes de mais nada, saber do que se está a falar, ou seja, é preciso definir, como o maior rigor possível, e segundo o entendimento dos principais defensores, o que é o consequencialismo, o que é o pragmatismo e o que é a análise econômica do direito. Somente após isso é possível fazer um verdadeiro trabalho de crítica. Crítica das verdadeiras ideias e conceitos, e não de versões atenuadas ou mesmo, no caso da abrasileirização, deformadas.
} 
Se a experiência da academia jurídica brasileira aponta para uma tendência a abrasileirar teorias importadas - um eco à Antropofagia dos Modernistas - este artigo se pretende uma espécie de antiengenharia reversa preventiva. Apresentar a correta definição das teorias, antes que o processo de deglutição se torne irreversível, é a forma de, ao menos idealmente, lutar contra a banalização e malversação de conceitos pelos operadores do Direito brasileiro. É lutar, assim, para que o consequencialismo, o pragmatismo e a Análise Econômica do Direito não sejam a nova Proporcionalidade.

\section{Referências}

ARAÚJO, Thiago Cardoso. Análise Econômica do Direito no Brasil: uma leitura à luz da Teoria dos Sistemas. Rio de Janeiro: Lumen Juris, 2017.

ARGUELHES, Diego Werneck; LEAL, Fernando. Pragmatismo como (meta)teoria normativa da decisão judicial: caracterização, estratégias e implicações. In: SARMENTO, Daniel (Org.). Filosofia e Teoria Constitucional Contemporânea. Rio de Janeiro: Lumen Juris, 2009, p. 171/211.

BINENBOJM, Gustavo, Uma teoria do direito administrativo direitos fundamentais, democracia e constitucionalização, Rio de Janeiro; São Paulo: Renovar, 2008.

BINENBOJM, Gustavo. Poder de Polícia, Ordenação, Regulação: transformações políticojurídicas, econômicas e institucionais do Direito Administrativo Ordenador. Belo Horizonte: Fórum, 2016.

BORGES VALADÃO, Rodrigo. A luta contra a teoria pura do direito na República de Weimar e o caminho para o nacional-socialismo. Revista Eletrônica da PGE-RJ, v. 3, n. 3, 30 dez. 2020.

COASE, Ronald. The problem of social cost. Journal of Law and Economics, v. 3, p. 1-44, out. de 1960.

COLEMAN, Jules. The Architecture of Jurisprudence. The Yale Law Journal, v. 121, n. 1, 2011. Disponível em: https://www.yalelaw journal.org/pdf/1009_3fnvkd8i.pdf. Acesso em: 30 out. 2020.

COOTER, Robert; Ulen, Thomas. Law \& Economics - 6a ed. Essex: Pearson, 2014.

COPLESTON, Frederick Charles. A History of Philosophy. [S. 1.]: Newman Press,. v. 8, p. 8. 1964.

CSERNE, Péter. Consequence-Based Arguments in Legal Reasoning: A Jurisprudential Preface to Law and Economics. In: Mathis K. (eds) Efficiency, Sustainability, and Justice to Future Generations. Law and Philosophy Library, vol 98. Springer, Dordrecht, 2012.

DAINOW, Joseph. The Civil Law and the Common Law: some points of comparison. The American Journal of Comparative Law, v. 15, n. 3, pp. 419-435. 1966-1967. Disponível em: <https://www.jstor.org/stable/838275>. Acesso em 17 de fev. de 2021.

DEMSETZ, Harold. Toward a Theory of Property Rights. The American Economic Review, v. 57, n. 2, Papers and Proceedings of the Seventy-ninth Annual Meeting of the American Economic Association. p. 347-359. 1967.

Disponível em: 
<https://www.jstor.org/stable/1821637?seq=1\#metadata_info_tab_contents>. Acesso em 29 de janeiro de 2021.

DWORKIN, Ronald. A justiça de toga. trad. Jefferson Luiz Camargo. São Paulo: WMF Martins Fontes, 2010.

ELLICKSON, Robert. Of Coase and cattle: a dispute resolution among neighbors in Shasta Count. Stanford Law Review, n. 38, p. 623-687, 1986. Disponível em: <https://www.jstor.org/stable/1228561?seq=1\#metadata_info_tab_contents>. Acesso em: 29 de janeiro de 2021.

Elster, Jon.Excessive Ambitions, Capitalism and Society: v.. 4, n. 2Iss. 2, artigo 1, pp. 1-33, 2009. Disponível em: https://papers.ssrn.com/sol3/papers.cfm?abstract_id=2209382\#. Acesso em 19 de mar. De 2021.DOI: 10.2202/1932-0213.1055.

FISH, Stanley. Doing What Comes Naturally: Change, Rhetoric, and the Practice of Theory in Literary \& Legal Studies. [S. 1.]: Duke University Press, 1989.

GICO JUNIOR, Ivo Teixeira. Notas sobre a Análise Econômica do Direito e Epistemologia do Direito. Direito UNIFACS, n. 160, 2013. Disponível em: < https://revistas.unifacs.br/index.php/redu/article/view/2794>. Acesso em 3 de março de 2021.

HAUSMAN, Daniel; MCPHERSON, Michael. Utilitarianism and Consequentialism. In: Economic Analysis, Moral Philosophy and Public Policy, $2^{\mathrm{a}}$ ed., pp. 99-117. Cambridge: Cambridge University Press, 2006. doi:10.1017/CBO9780511754289.010.

JAMES, William. Pragmatism: a new name for some old ways of thinking. Cambridge: Cambridge University Press, 2014.

JOHNSTON, David. Breve história da justiça. São Paulo: WWF Martins Fontes, 2018.

KOROBKIN, Russel; ULEN, Thomas. Law and Behavioral Science: Removing the Rationality Assumption from Law and Economics. California Law Review, vol. 88, n. 4, p. 1051-1144. 2000.

LANGDELL, Christopher Columbus. Selection of cases on the law of Contracts. Boston: Little, Brown and Company, 1879.

LEAL, Fernando. Regulando a incerteza: a construção de modelos decisórios e os riscos do paradoxo da determinação. Revista de investigações constitucionais, Curitiba, v. 3, n. 3, p. 219, set./ dez. 2016.)

LEITER, Brian. Legal Realism, Hard Positivism, and the Limits of Conceptual Analysis. In: . Naturalizing Jurisprudence: Essays on American Legal Realism and Naturalism in Legal Philosophy. Nova Iorque: Oxford University Press, 2007, p. 121-135.

MARÍAS, Julián. História da Filosofia. São Paulo: Martins Fontes, 2004.

MARTINS, Daniela Berwanger; PAZETO, Matheus Lolli. Breves linhas sobre a inclusão da Análise Econômica do Direito na prolação de uma decisão judicial. In: Reflexões sobre Direito e 
Economia (Armando Castelar Pinheiro et al. org). pp. 145-164. Rio de Janeiro: FGV Direito Rio, 2020.

MATHIS, Klaus. Consequentialism in Law. In: Efficiency, Sustainability, and Justice to Future Generations, 3 Law and Philosophy Library, 1998.

MAXIMILIANO, Carlos. Hermenêutica e aplicação do direito. Rio de Janeiro: Forense, 2011, p. 165

MENAND, Louis. The Metaphysical Club: a Story of Ideas in America. Nova York: Farrar, Straus \& Giroux. 2001.

MENDES, Conrado Hübner. Jurisprudência impressionista. Época, 14 set. 2018. Disponível em: <https://epoca.globo.com/conrado-hubner-mendes/jurisprudencia-impressionista-23066592>

Acesso em 17 de fev. de 2021.

MENDONÇA, José Vicente Santos de. A verdadeira mudança de paradigma do direito administrativo brasileiro: do estilo tradicional ao novo estilo. Revista de Direito Administrativo. Rio de Janeiro, v. 265, p. 178/198, jan/abr. de 2014.

PARGLENDER, Mariana, SALAMA, Bruno. Direito e consequência no Brasil: em busca de um discurso sobre o método. Revista de Direito Administrativo, v. 262, p. 95-144, jan./abr. 2013.

PEIRCE, Charles Sanders. How to make our Ideas clear. Popular Science Monthly, v. 12, p. 286302, jan. 1878.

PETROSKI, Karen. Is Post-Positivism possible? German Law Review, v. 12, n. 2, p. 663-692, fev. de 2011.

POGREBINSCHI, Thamy. Será o neopragmatismo pragmatista? Interpelando Richard Rorty. Novos estud. - CEBRAP, São Paulo , n. 74, p. 125-138, Mar. 2006. Disponível em: $<$ http://www.scielo.br/scielo.php?script=sci_arttext\&pid=S0101-

$33002006000100008 \& \operatorname{lng}=$ en\&nrm=iso>. Acesso em 28 Jan. 2021.

POSNER, Richard A. Breaking the Deadlock: The 2000 Election, the Constitution, and the Courts. [S. 1.]: Princeton University Press, 2001.

POSNER, Richard A. Law, Pragmatism, and Democracy. [S. 1.]: Harvard University Press, 2005.

POSNER, Richard. Bush v. Gore as Pragmatic Adjudication, in: A Badly Flawed Election: Debating Bush v. Gore, the Supreme Court, and American Democracy, Ronald Dworkin eds., 2002.

POSNER, Richard. Law, Pragmatism and Democracy. Cambridge, MA: Harvard University Press. 2003. P. 60-61

POSNER, Richard. Law, Pragmatism and Democracy. Cambridge, MA: Harvard University Press, 2003, p. 333.

POSNER, Richard. The Value of Wealth: a comment on Dwokin and Kronman. The Journal of Legal Studies, v. 9, n. 2, pp. 243-252, mar. 1980. 
RESSING, Maximilian. Prinzipien als Normen mit zwei Geltungsebenen: zur Untersheidung von Regeln und Prinzipien. Archiv für Rechts und Sozialphilosophie, v. 95, n. 1, p. 28-48, 2009.

SALAMA, Bruno. “O que é Direito e Economia?”. Direito UNIFACS, n. 160, 2013. Disponível em: < https://revistas.unifacs.br/index.php/redu/article/view/2793/2033>. Acesso em 3 de março de 2021.

SCHEFFLER, Samuel. Consequentialism and its critics. Oxford: Oxford University Press, 1988.

SCHWARTZ, Gary T. Reality in the economic analysis of tort law: does tort law really deter. UCLA Law Review, v. 42, p. 377, 1994. Disponível em: <https://heinonline.org/HOL/Page?public=true\&handle=hein.journals/uclalr42\&div=17\&start_pa ge $=377 \&$ collection $=$ journals \&set_as_cursor $=2 \&$ men_tab $=$ srchresults $>$. Acesso em: 29 de janeiro de 2021.

SCHWARZ, Roberto. As ideias fora do lugar. In: "Ao vencedor as batatas", São Paulo: Duas Cidades, $4^{\text {a }}$ edição, 1992, pp. 1-16.

SHAVELL, Steven. Specific Performance Versus Damages for Breach of Contract: An Economic Analysis. Texas Law Review, v. 84, n. 4, p. 831. 2006. Disponível em: <http://www.law.harvard.edu/faculty/shavell/pdf/Shavell-SpecPerf-06.pdf >. Acesso em: 29 de janeiro de 2021.

SILVA, Virgílio Afonso da. O proporcional e o razoável. Revista dos Tribunais, n. 798, p. 23-50, 2002.

SUIKKANEN, Jussi. Consequentalism, constraints and the good-relative-to: a reply to Mark Schroeder. Journal of Ethics \& Social Philosophy. Discussion note, mar. 2009.

SUNDFELD, Carlos Ari. Princípio é preguiça? In: Ronaldo Porto Macedo Jr. e Catariana Barbieri (org). Direito e interpretação - racionalidades e instituições. São Paulo: Saraiva, 2011, pp. 287 305.

TASIOULAS, John. Conceptual overreach threatens the quality of public reason. Aeon, seç. Philosophy, [s. $\left.\begin{array}{ll}s .\end{array}\right]$. Disponível em: https://aeon.co/essays/conceptual-overreach-threatens-thequality-of-public-reason. Acesso em: 3 fev. 2021.

THORNTON, Stephen. "Karl Popper". The Stanford Encyclopedia of Philosophy (Spring 2021 Edition), Edward N. Zalta (ed.), no prelo. Disponível em: <https://plato.stanford.edu/archives/spr2021/entries/popper/>. Acesso em 18 de fev. de 2021.

ULEN, Thomas. A Nobel Prize in Legal Science: Theory, Empirical Work, and the Scientific Method in the Study of Law. University of Illinois Law Review, v. 2002, n. 4, pp. 875-920.

WEAVER. Richard M. M. As ideias têm consequências. São Paulo: É Realizações, 2012.

ZANATTA, Rafael. Desmistificando a Law \& Economics: a Receptividade da Disciplina Direito e Economia no Brasil. Revista dos Estudantes de Direito da UNB (REDUnB), v. 10, 2012. 